\title{
Article \\ Predictors for Adherence to Treatment Strategies in Elderly HNSCC Patients
}

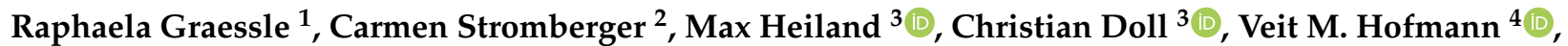 \\ Konrad Klinghammer ${ }^{5,6}{ }^{(}$, Ingeborg Tinhofer ${ }^{2}$, Heidi Olze ${ }^{1}$, Marcus Beck ${ }^{2}{ }^{\circledR}$, Philipp Arens ${ }^{1}$, \\ Steffen Dommerich ${ }^{1}$, Iris Piwonski ${ }^{7}$ and Annekatrin Coordes ${ }^{1, *(1)}$
}

1 Department of Otorhinolaryngology, Head and Neck Surgery, Campus Virchow Klinikum and Campus Charité Mitte, Charité—Universitätsmedizin Berlin, Freie Universität Berlin, Humboldt-Universität zu Berlin, and Berlin Institute of Health, 10117 Berlin, Germany; raphaela.graessle@charite.de (R.G.); heidi.olze@charite.de (H.O.); philipp.arens@charite.de (P.A.); steffen.dommerich@charite.de (S.D.)

2 Department of Radiooncology, Charité-Universitätsmedizin Berlin, Freie Universität Berlin, Humboldt-Universität zu Berlin, and Berlin Institute of Health, 10117 Berlin, Germany; carmen.stromberger@charite.de (C.S.); ingeborg.tinhofer@charite.de (I.T.); marcus.beck@charite.de (M.B.)

3 Department of Oral and Maxillofacial Surgery, Campus Virchow Klinikum and Campus Benjamin Franklin, Charité-Universitätsmedizin Berlin, Freie Universität Berlin, Humboldt-Universität zu Berlin, and Berlin Institute of Health, 10117 Berlin, Germany; max.heiland@charite.de (M.H.); christian.doll@charite.de (C.D.)

4 Department of Otorhinolaryngology, Head and Neck Surgery, Campus Benjamin Franklin, Charité-Universitätsmedizin Berlin, Freie Universität Berlin, Humboldt-Universität zu Berlin, and Berlin Institute of Health, 10117 Berlin, Germany; veit.hofmann@charite.de

5 Department of Hematology and Oncology, Campus Benjamin Franklin, Charité-Universitätsmedizin Berlin, Freie Universität Berlin, Humboldt-Universität zu Berlin, and Berlin Institute of Health, 10117 Berlin, Germany; konrad.klinghammer@charite.de

6 Charité Comprehensive Cancer Center, 10117 Berlin, Germany

check for

Citation: Graessle, R.; Stromberger, C.; Heiland, M.; Doll, C.; Hofmann, V.M.; Klinghammer, K.; Tinhofer, I.; Olze, H.; Beck, M.; Arens, P.; et al. Predictors for Adherence to Treatment Strategies in Elderly HNSCC Patients. Cancers 2022, 14, 423. https://doi.org/10.3390/ cancers14020423

Academic Editor: Gino Marioni

Received: 17 December 2021

Accepted: 13 January 2022

Published: 14 January 2022

Publisher's Note: MDPI stays neutral with regard to jurisdictional claims in published maps and institutional affiliations.

Copyright: (c) 2022 by the authors. Licensee MDPI, Basel, Switzerland. This article is an open access article distributed under the terms and conditions of the Creative Commons Attribution (CC BY) license (https:// creativecommons.org/licenses/by/ $4.0 /)$.
7 Department of Pathology, Charité-Universitätsmedizin Berlin, Freie Universität Berlin, Humboldt-Universität zu Berlin, and Berlin Institute of Health, 10117 Berlin, Germany; iris.piwonski@charite.de

* Correspondence: annekatrin.coordes@charite.de; Tel.: +49-30-450-555-002

Simple Summary: The aim of this study was to find predictors for adherence to a therapy recommended by a multidisciplinary tumour board regarding 1125 elderly patients (70-100 years) with head and neck squamous cell carcinoma (HNSCC). The 5-year overall survival was significantly higher in adherent patients ( $45.1 \%$ versus $19.2 \%$ ). Nonadherent patients were significantly more often smokers, drinkers, and had a worse tumour stage and lower health status (Karnofsky performance status). In contrast to the chronological patient age, the biological age (Charlson Comorbidity Index) was a significant predictor for adherence. The evaluated predictors for nonadherence need to be verified prospectively.

\begin{abstract}
Finding a cure may be less important than ensuring the quality of life in elderly patients with head and neck squamous cell carcinoma (HNSCC). The aim of this study was to determine predictors for adherence. Clinical and pathological data from patients $\geq 70$ years with HNSCC (initial diagnoses 2004-2018) were investigated retrospectively. Evaluated clinical predictors included biological age (Charlson Comorbidity Index; CCI), patient health (Karnofsky Performance Status; KPS) and therapy data. A total of 1125 patients were included. The median age was 75 years, 33.1\% reached CCI $\geq 6$, and $53.7 \%$ reached KPS $\leq 70 \%$. In total, 968 patients were adherent, whereas 157 were nonadherent. Nonadherent patients were significantly more often smokers $(p=0.003)$, frequent drinkers $(p=0.001)$, had a worse health status $(p \leq 0.001)$ and a lower biological age $(p=0.003)$, an advanced T classification and lymph node involvement or UICC stage (each $p \leq 0.001)$. Approximately $88.0 \%$ of the included patients received a curative treatment recommendation. A total of $6.9 \%$ discontinued the therapy, and $7.0 \%$ refused the therapy. With the increasing complexity of a recommended therapy, adherence decreased. The 5-year overall survival was significantly higher in adherent patients (45.1\% versus $19.2 \%$ ). In contrast to the chronological patient age, biological age is a significant predictor for adherence. The evaluated predictors for nonadherence need to be verified prospectively.
\end{abstract}


Keywords: head and neck squamous cell carcinoma; elderly patients; adherence; therapy; survival

\section{Introduction}

Life expectancy in the European Union has increased significantly from 77 in 2000 to 81 years in 2018 [1]. In Germany, life expectancy is 81 [2]. Therefore, the number of older patients with head and neck squamous cell carcinoma (HNSCC) has increased. Due to demographic change, by 2030, there may be an increase of $66 \%$ in laryngeal carcinomas and $61 \%$ in oral cavity or pharyngeal carcinomas in patients older than 65 , compared to 2010 [3]. However, elderly patients are underrepresented in clinical trials. The proportion of patients $\geq 75$ years generally represents less than $10 \%$ of study populations [4]. Due to this current data gap, a standard of care for this patient subgroup needs to be established [5]. Therapeutic recommendations are largely based on the medical assessment of the treating physicians and/or on clinic-specific guidelines. The need for standardised guidelines for the elderly is further supported by the fact that the older patients become, the more likely they are not to receive therapy according to the current standard. Older HNSCC patients have a significantly higher probability of being treated with palliative rather than curative therapy compared to younger patient groups [6-8].

Even though comorbidities are more common in geriatric patients and lead to a larger amount of non-standard treatment regardless of age, they are not the only explanation for this difference. Age itself seems to play a significant role. For instance, only $2 \%$ of patients between 45 and 60 without comorbidities do not receive a guideline-based therapy, whereas more than $10 \%$ of patients older than 70 , also without comorbidities, are treated with nonstandard therapies [7]. In this context, one must keep in mind that chronological age should not prevent patients from receiving curative treatment [9]. The comorbidities that increase the probability of treatment-related adverse events and predict a disadvantageous outcome are of higher importance [10-13].

Additionally, individual patients' preferences are decisive in the choice of therapy. Being cured is not the most important objective for HNSCC patients in every case [14]. Older patients tend to put more emphasis on quality of life, and overall survival (OS) is less important to them [15].

In order to better understand the complex situation regarding the choice of treatment in older HNSCC patients, our primary objective was to determine predictors by which elderly patients decide whether to decline or discontinue therapies proposed by a multidisciplinary tumour board. Secondly, we attempted to find predictors for OS in elderly patients with HNSCC. Thirdly, we examined if there are OS predictors particular to adherent and nonadherent patients.

\section{Materials and Methods}

\subsection{Patient Inclusion Criteria}

The present study included HNSCC patients aged 70 years or older who were treated at the Charité-Universitätsmedizin Berlin between 2004 and 2018. In all cases, HNSCC was confirmed histologically. The following subsites of HNSCC were included: larynx, oro-/naso-/hypopharynx, oral cavity and nasal/paranasal sinuses. Clinicopathological data of all patients were documented and retrospectively extracted from electronic patient records. The study was approved by the local ethics committee $(E A 1 / 256 / 20)$.

\subsection{Patient and Treatment Assessment}

Each patient underwent common diagnostic procedures at our institution. This included a precise medical history and an examination of the head and neck, including endoscopy. Radiological investigations generally included a computed tomography (CT) scan or magnetic resonance imaging of the neck and a CT scan of the thorax and abdomen. Furthermore, patients underwent a panendoscopy to evaluate the tumour extension, exclude 
synchronic tumours and take tissue biopsies. Tissue samples of oropharyngeal squamous cell carcinoma were examined by immunohistochemistry to detect the expression of p16 as a surrogate marker for HPV association [16]. Since 2017, p16 was routinely stained. In previous cases, p16 status was investigated whenever sufficient samples were available. To compare patients adequately, the 8th edition of the UICC TNM classification, which takes account of p16 status, was used [17]. Oropharyngeal carcinomas for which no tissue sample was available for staining were therefore assumed to be $\mathrm{p} 16$ negative for purposes of TNM classification. For all other purposes, the p16 status of these cases was classified as "not applicable". The treatment in all cases was planned based on a multidisciplinary head and neck tumour board recommendation (head and neck surgeons, medical and radiation oncologists, pathologists and radiologists). Patients who followed the board's recommendation were considered to be adherent; the other patients (who discontinued or rejected the recommended therapy) were considered as nonadherent. The patients decided whether to follow the proposed therapy after an explanatory conversation with their attending physician, which addressed their needs and concerns. The ultimate decision of whether to follow the proposed therapy lay with the patient. Therapeutic recommendations by the tumour board were individual because comorbidities, especially with advanced age, sometimes limited the reasonable therapy options considerably. The medical condition of each patient prior to the therapy was taken into account using the Karnofsky performance status (KPS) [18]. For this study, comorbidities were scored retrospectively using the Charlson Comorbidity Index (CCI) based on the patients' documented secondary diagnoses [19]. The CCI was used to represent the biological age of patients.

The surgical procedure aimed at an in-sano resection. A tracheostomy was used as a surgical procedure to secure the airway pathway. In tumours $\geq \mathrm{T} 3$ or histologically confirmed lymph node involvement, adjuvant radiotherapy/radiochemotherapy (RT/RCT) was indicated.

Adjuvant RT was usually performed using 54 to $66 \mathrm{~Gy}$. In cases with high-risk features, $66 \mathrm{~Gy}$ and concomitant chemotherapy were used: in cases of resection with a close margin $(<5 \mathrm{~mm})$, or nodal extracapsular spread (ENE), tumour resection with microscopically detected tumour cells in the surgical margins (R1). Concomitant chemotherapy consisted of cisplatin $\left(5 \times 20 \mathrm{mg} / \mathrm{m}^{2}, 1\right.$. and 5 weeks of RT, or weekly $\left.30 \mathrm{mg} / \mathrm{m}^{2}\right) \pm 5$-fluorouracil (5FU, $5 \times 600 \mathrm{mg} / \mathrm{m}^{2}$ c.i., 1 st week of RT), or in the definitive setting, alternatively mitomycin $\mathrm{C}\left(2 \times 10 \mathrm{mg} / \mathrm{m}^{2}, \mathrm{~d} 1\right.$ and d29) $\pm 5 \mathrm{FU}\left(5 \times 600 \mathrm{mg} / \mathrm{m}^{2}\right.$ c.i., 1st week of RT) or cetuximab ( $400 \mathrm{mg} / \mathrm{m}^{2}$ preload, and $250 \mathrm{mg} / \mathrm{m}^{2}$ weekly to RT).

Alternatively, definitive RT/RCT (>70 Gy) was performed (e.g., in the case of advanced nodal categories). Patients with stage I-II disease received definitive RT with 66-70 Gy according to international treatment guidelines (e.g., NCCN HN V1.2022). Patients with locally advanced HNSCC with multiple comorbidities, frailty and/or poor health who did not qualify for concurrent RCT had curative RT $\geq 70$ Gy in altered fractionation (hyperfractionation) or normofractionation.

In some cases, including those with poor general health, palliative RT/RCT, systemic therapy (ST) including palliative chemotherapy or immunotherapy (e.g., cetuximab and nivolumab), or Best Supportive Care (BSC) were suggested by the tumour board.

\subsection{Statstical Analysis}

The data set was analysed using IBM SPSS Statistics version 26.0.0.0 for macOS (IBM Corp., Armonk, NY, USA).

Patients' characteristics were reported according to the sample Guidelines [20]. Data not normally distributed, (pack years and age at initial diagnosis) was summarised with medians and ranges with minimum and maximum values. For statical processing, several variables were converted into dichotomous values. In this study, an exploratory data analysis was performed, and all $p$-values were reported without adjustment for multiple testing.

The primary objective was to identify constitutional differences in adherent and nonadherent patients. The chi-square test was used to test the categorical variables of characteristics 
among adherent and nonadherent patients for significant differences. The Mann-Whitney $\mathrm{U}$ test was used with the same intention for the metric, non-normally distributed variables. The following clinicopathological variables were recorded: sex (male vs. female), age at initial diagnosis of HNSCC, tobacco exposure (non-smoker vs. former/current smoker), pack years, alcohol abuse (no ethanol consumption vs. ethanol consumption), additional cancer diagnoses (other cancers vs. none), number of additional cancer diagnoses ( 0 vs. 1 vs. $\geq 2$ ), CCI ( $\leq 5$ vs. $\geq 6$ ), KPS ( $\leq 70 \%$ vs. $\geq 80 \%$ ), death due to cancer (survived vs. non-cancer-associated vs. cancer-associated), tumour site (oropharynx vs. oral cavity vs. larynx vs. hypopharynx vs. nasal/paranasal sinus vs. nasopharynx), p16 in oropharynx carcinomas only (positive vs. negative), tumour grading (G1 vs. G2 vs. G3), T classification (T1-2 vs. T3-4), N classification (positive vs. negative), M classification (positive vs. negative), UICC stage (I-II vs. III-IV), received treatment (BSC vs. pall. RT/RCT vs. surgery vs. surgery + adj. RT/RCT vs. def. RT/RCT vs. ST), recommended treatment (BSC vs. pall. RT/RCT vs. surgery vs. surgery + adj. RT/RCT vs. def. RT/RCT vs. ST), intention of therapy (curative vs. palliative vs. curative, discontinued) and implementation of therapy (discontinued vs. rejected vs. carried out).

Secondly, OS and disease-free survival (DFS) of the patient cohort was analysed using the Kaplan-Meier method. We proceeded to a univariant analysis to identify variables that significantly influence OS. For this purpose, the log-rank test was used. The OS was defined as the time between the initial diagnosis of the HNSCC and the date of death or last follow-up. Almost the same variables were included; only pack years, the number of additional cancer diagnoses and death due to cancer were not analysed. DFS was defined as the time between the initial diagnosis of the HNSCC and the time of recurrence, death or last follow-up. The log-rank test was used to analyse the influence of adherence on DFS.

For multivariate analyses of OS, the Cox proportional hazards model was used. The following variables were considered: age at initial diagnosis of HNSCC, tobacco exposure, CCI, KPS, UICC stage and adherence to treatment recommendation.

For all tests, $p$-values $<0.05$ were assumed to be statistically significant.

\section{Results}

\subsection{Patient Characteristics}

During the study period, 1353 patients aged 70 years or older were diagnosed with HNSCC at the Charité-Universitätsmedizin Berlin. The present study included 1125 of these patients. In all patients, a complete tumour stage, a recommendation by the multidisciplinary tumour board on treatment and the course of therapy were documented. In the remaining 228 patients, the data was incomplete. The clinicopathological data is outlined in Table 1.

The study population contained chiefly male patients $(n=759,67.5 \%)$; the median age was 75 and ranged from 70 to 100 . In 641 patients $(57.0 \%)$, smoking status could be investigated; $65.5 \%(n=420)$ of patients were current or former smokers. In 262 patients, the number of pack years (PY) with a median of 50 PY (range: 3-200 PY) was recorded. Alcohol consumption was documented for 633 patients, and 199 (31.4\%) patients regularly consumed alcohol. Approximately 33.1\% $(n=372)$ had a history of cancer other than HNSCC.

The study population had a mixed health status: $33.1 \%$ of the cases reached a CCI $\geq 6$, whereas $46.3 \%$ of patients achieved more than $80 \%$ on the KPS. A total of $627(55.7 \%)$ patients died during the follow-up period of up to 170 months (range: 0-170; median 23 months), $67.9 \%(n=426)$ of these deaths were known to be related to the HNSCC diagnosis. 
Table 1. Patient and tumour characteristics of the study population according to adherence/nonadherence to the tumour board recommendation.

\begin{tabular}{|c|c|c|c|c|}
\hline Variablo & Total & Adherence & Nonadherence & $p$-Value \\
\hline vanidore & $n=1125$ & $n=968$ & $n=157$ & \\
\hline Sex-no. $(\%)$ & & & & 0.572 \\
\hline Male & $759(67.5)$ & $650(67.1)$ & $109(69.4)$ & \\
\hline Female & $366(32.5)$ & $318(32.9)$ & $48(30.6)$ & \\
\hline Age at initial diagnosis of HNSCC, years & & & & 0.810 \\
\hline Median (range) & $75(30)$ & $75(30)$ & $75(24)$ & \\
\hline Tobacco exposure-no. (\%) & & & & 0.003 \\
\hline Non-smoker & $221(34.5)$ & $203(36.7)$ & $18(20.5)$ & \\
\hline Current/former smoker & $420(65.5)$ & $350(63.3)$ & $70(79.5)$ & \\
\hline Pack years & & & & 0.013 \\
\hline Median (range) & 50 (197) & 50 (147) & 50 (195) & \\
\hline Alcohol abuse-no. (\%) & & & & 0.001 \\
\hline No ethanol consumption & $434(68.6)$ & $391(71.0)$ & $43(52.4)$ & \\
\hline Ethanol consumption & $199(31.4)$ & $160(29.0)$ & $39(47.6)$ & \\
\hline Additional cancer diagnoses-no. (\%) & & & & 0.369 \\
\hline Other cancers & $372(33.1)$ & $325(33.6)$ & $47(29.9)$ & \\
\hline None & $753(66.9)$ & $643(66.4)$ & $110(70.1)$ & \\
\hline Number of additional cancer diagnoses & & & & 0.642 \\
\hline 0 & $753(66.9)$ & $643(66.4)$ & $110(70.1)$ & \\
\hline 1 & $291(25.9)$ & $255(26.3)$ & $36(22.9)$ & \\
\hline$\geq 2$ & $81(7.2)$ & $70(7.2)$ & $11(7.0)$ & \\
\hline Charlson Comorbidity Index-no. (\%) & & & & 0.003 \\
\hline$\leq 5$ & $753(66.9)$ & $664(68.6)$ & $89(56.7)$ & \\
\hline$\geq 6$ & $372(33.1)$ & $304(31.4)$ & $68(43.3)$ & \\
\hline Karnofsky Performance Status-no. (\%) & & & & $\leq 0.001$ \\
\hline$\leq 70 \%$ & $604(53.7)$ & $482(49.8)$ & $122(77.7)$ & \\
\hline$\geq 80 \%$ & $521(46.3)$ & $486(50.2)$ & $35(22.3)$ & \\
\hline Death due to cancer & & & & $\leq 0.001$ \\
\hline Survived & $496(48.8)$ & $461(52.7)$ & $35(24.6)$ & \\
\hline Non-cancer-associated & $94(9.3)$ & $87(10.0)$ & $7(4.9)$ & \\
\hline cancer-associated & $426(41.9)$ & $326(37.3)$ & $100(70.4)$ & \\
\hline \multicolumn{5}{|l|}{ HNSCC characteristics } \\
\hline Site of primary tumour-no. (\%) & & & & $0.335^{1}$ \\
\hline Oropharynx & $305(27.1)$ & $252(26.0)$ & $53(33.8)$ & \\
\hline Oral cavity & 449 (39.9) & $393(40.6)$ & $56(35.7)$ & \\
\hline Larynx & $215(19.1)$ & $186(19.2)$ & $29(18.5)$ & \\
\hline Hypopharynx & $95(8.4)$ & $81(8.4)$ & $14(8.9)$ & \\
\hline Nasal/paranasal sinuses & $43(3.8)$ & $39(4.0)$ & $4(2.5)$ & \\
\hline Nasopharynx & $18(1.6)$ & $17(1.8)$ & $1(0.6)$ & \\
\hline
\end{tabular}


Table 1. Cont.

\begin{tabular}{|c|c|c|c|c|}
\hline \multirow{2}{*}{ Variable } & Total & Adherence & Nonadherence & $p$-Value \\
\hline & $n=1125$ & $n=968$ & $n=157$ & \\
\hline P16 in Oropharynx-Carcinoma-no. $(\%)$ & & & & 0.521 \\
\hline Positive & $93(51.1)$ & $75(50.0)$ & $18(56.3)$ & \\
\hline Grading-no. (\%) & & & & 0.002 \\
\hline G1 & $105(10.3)$ & $99(11.4)$ & $6(4.7)$ & \\
\hline G2 & $657(64.7)$ & $569(65.3)$ & $88(61.5)$ & \\
\hline G3 & $253(24.9)$ & $204(23.5)$ & $49(34.3)$ & \\
\hline $\mathrm{T}$ classification $(\mathrm{T})-$ no. $(\%)$ & & & & $\leq 0.001$ \\
\hline T1-2 & $586(52.1)$ & $536(55.4)$ & $50(31.8)$ & \\
\hline T3-4 & $539(47.9)$ & $432(44.6)$ & $107(68.2)$ & \\
\hline N classification-no. $(\%)$ & & & & $\leq 0.001$ \\
\hline Positive & $543(48.3)$ & $445(46.0)$ & $98(62.4)$ & \\
\hline M classification-no. (\%) & & & & 0.087 \\
\hline Positive & $44(3.9)$ & $34(3.5)$ & $10(6.4)$ & \\
\hline UICC stage (8th edition)—no. (\%) & & & & $\leq 0.001$ \\
\hline I-II & $451(40.1)$ & $422(43.6)$ & $29(18.5)$ & \\
\hline III-IV & $674(59.9)$ & $546(56.4)$ & $128(81.5)$ & \\
\hline Intention of therapy & & & & $\leq 0.001$ \\
\hline Curative & $860(76.4)$ & $860(88.8)$ & - & \\
\hline Palliative & $183(16.3)$ & $108(11.2)$ & $77(47.8)$ & \\
\hline Curative, discontinued & $82(7.3)$ & - & $82(52.2)$ & \\
\hline
\end{tabular}

HNSCC, head and neck squamous cell carcinoma; UICC, Union for International Cancer Control. ${ }^{1}$ The requirements to perform a chi-square test were not fulfilled.

Tumours affected the oropharynx $(n=305,27.1 \%)$, oral cavity $(n=449,39.9 \%)$, larynx $(n=215,19.1 \%)$, hypopharynx $(n=95,8.4 \%)$, nasal/paranasal sinuses $(n=43,3.8 \%)$ and nasopharynx $(n=18,1.6 \%)$. Predominantly, the patients' tumour stage was advanced $(59.9 \%$ UICC III-IV) at the time of the initial diagnosis. In total, $47.9 \%(n=539)$ of the study population were classified T3-4 and in $48.3 \%$ of cases $(n=543)$ regional lymph nodes were affected by the HNSCC. Distant metastases were found in 44 patients $(3.9 \%)$ at the time of diagnosis of HNSCC.

All tumours were confirmed histologically as being of squamous cell origin, and were graded as G1 $(n=105,10.3 \%), \mathrm{G} 2(n=657,64.7 \%)$ or G3 $(n=253,24.9 \%)$. In $59.7 \%$ of oropharyngeal carcinomas $(n=182)$, the p16-status was available. It was positive in $51.1 \%$ of cases $(n=93)$.

The treatment recommendation of the multidisciplinary tumour board included (Figure 1): surgery $(n=393,34.9 \%)$, definitive RT/RCT $(n=351,31.2 \%)$, surgery with adjuvant RT/RCT $(n=246,21.9 \%)$, palliative RT/RCT $(n=94,8.4 \%), \mathrm{BSC}(n=28,2.5 \%)$ and ST $(n=13,1.2 \%)$. The tumour board recommended a curative therapy in $88.0 \%(n=990)$ of cases. In $6.9 \%$ (78/1125) of cases, recommended therapy was discontinued $(n=78)$ and in $7.0 \%$ of cases the recommended therapy was rejected $(n=79)$. The treatments received included: surgery $(n=449,39.9 \%)$, definitive RT/RCT $(n=309,27.5 \%)$, surgery with adjuvant RT/RCT $(n=184,16.4 \%)$, palliative RT/RCT $(n=89,7.9 \%)$, BSC $(n=80,7.1 \%)$ and ST $(n=14,1.2 \%)$. The intention of the treatments that were actually implemented was also curative in most cases ( $n=860,76.4 \%$ ). 
A. Treatment recommendation

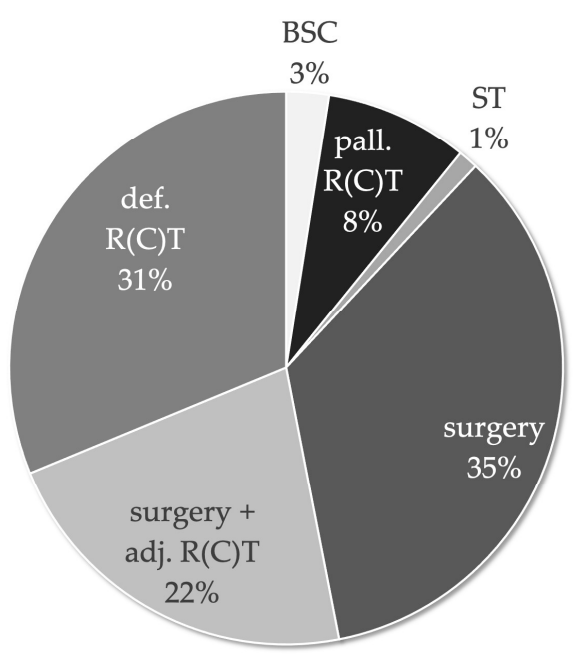

B. Treatment received

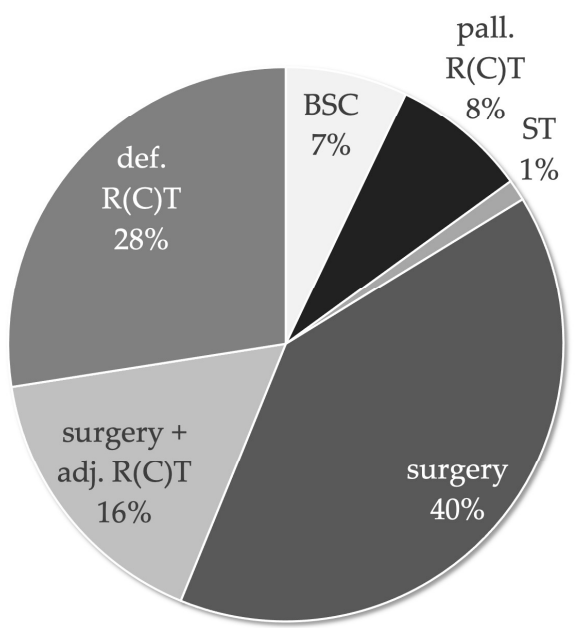

Figure 1. Treatment recommendations of the multidisciplinary tumour board of 1125 patients with HNSCC $\geq 70$ years. (A). Treatment recommended and (B). treatment received.

Table 2 show a cross-table comparing the therapy recommended by the tumour board to the therapy actually received. Eighty-two patients $(7.3 \%)$ originally started with a curative therapy but did not follow through until completion. Approximately $16.3 \%$ of the study population received treatment with palliative intent $(n=183)$. The median total dose of curative and palliative radiation was 70.0 and $45.0 \mathrm{~Gy}$, respectively (45.0-75.6 Gy and 15.0-60.0 Gy).

Table 2. Cross-table comparing the recommended therapy to the received therapy.

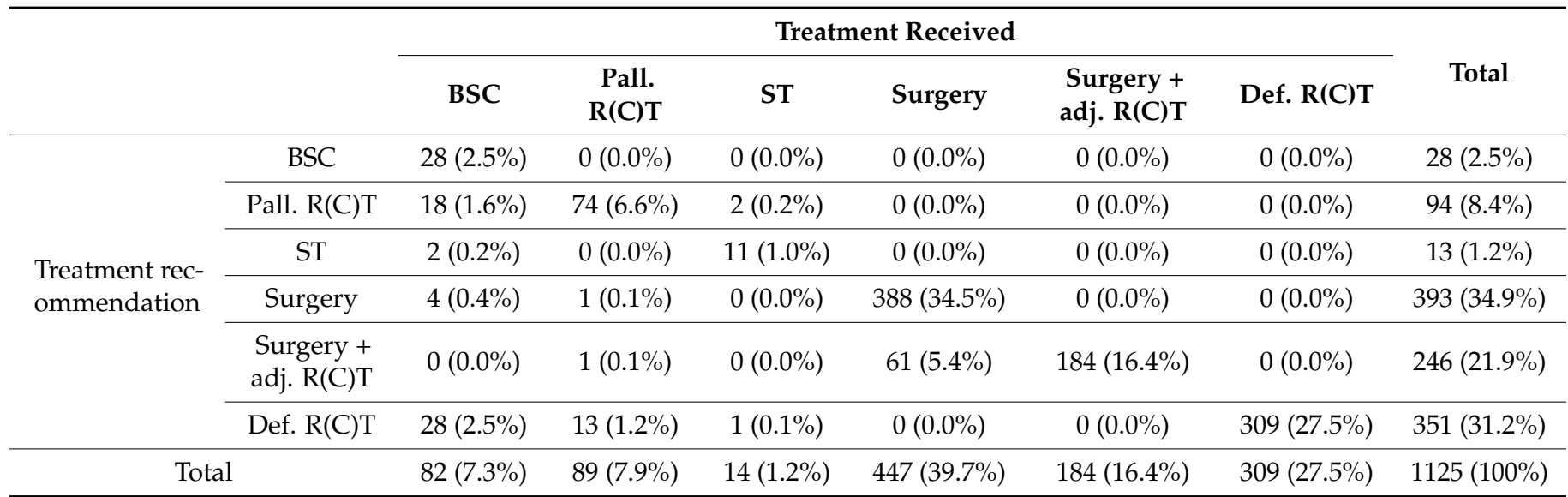

BSC, Best Supportive Care; Pall. R(C)T, palliative radio(chemo)therapy; ST, systemic therapy; Adj. R(C)T, adjuvant radio(chemo)therapy; Def. $\mathrm{R}(\mathrm{C}) \mathrm{T}$, definitive radio(chemo)therapy.

\subsection{Predictors for Nonadherence}

According to their adherence to the tumour board recommendation, patients were divided into adherent $(n=968,86.0 \%)$ and nonadherent $(n=157,14.0 \%)$ groups. The TNM classification and UICC stage were significantly more advanced in the nonadherent subgroup (T $p \leq 0.001 ; \mathrm{N} p \leq 0.001$; UICC $p \leq 0.001)$. In total, 81.5\% $(n=128)$ of nonadherent patients were diagnosed with a UICC stage III-IV compared to $56.4 \%(n=546)$ of adherent patients. Nonadherent patients died significantly more often in association with their tumour than adherent patients $(70.4 \%$ versus $37.3 \% ; p \leq 0.001)$. Significant differences in the constitution of the groups were found in tobacco exposure $(p=0.003)$ and alcohol abuse $(p=0.001)$. Approximately $63.3 \%(n=350)$ of all adherent patients were smokers, in contrast to $79.5 \%(n=70)$ of nonadherent patients. Of all the adherent patients, $29.0 \%$ 
( $n=160)$ consumed larger quantities of alcohol, in contrast to $47.6 \%(n=39)$ of nonadherent patients. There was also a difference in the patients' health status (KPS $p \leq 0.001$ ). A total of $49.8 \%(n=482)$ of the adherent subgroup versus $77.7 \%(n=122)$ of the nonadherent group did not achieve more than $80 \%$ on the KPS. Biological age was significantly lower in nonadherent patients (CCI $p=0.003)$, while chronological age did not have any influence. A CCI of 6 or more was present in $31.4 \%(n=304)$ of cases in the adherent subgroup versus $43.3 \%(n=68)$ in the nonadherent subgroup.

In the adherent group, the therapy performed was, by definition, identical to the recommended therapy. The recommended curative treatment in nonadherent patients (Figure 2) was surgery with adjuvant RT/RCT in $43.3 \%$ of cases, surgery alone in $5.1 \%$ and definitive $\mathrm{RT} / \mathrm{RCT}$ in $34.4 \%$. By contrast, $3.8 \%$ of nonadherent patients actually received surgery with adjuvant RT/RCT, 40.8\% received surgery only and 7.6\% received definitive RT/RCT.

\section{A. Treatment recommendation} (nonadherence)

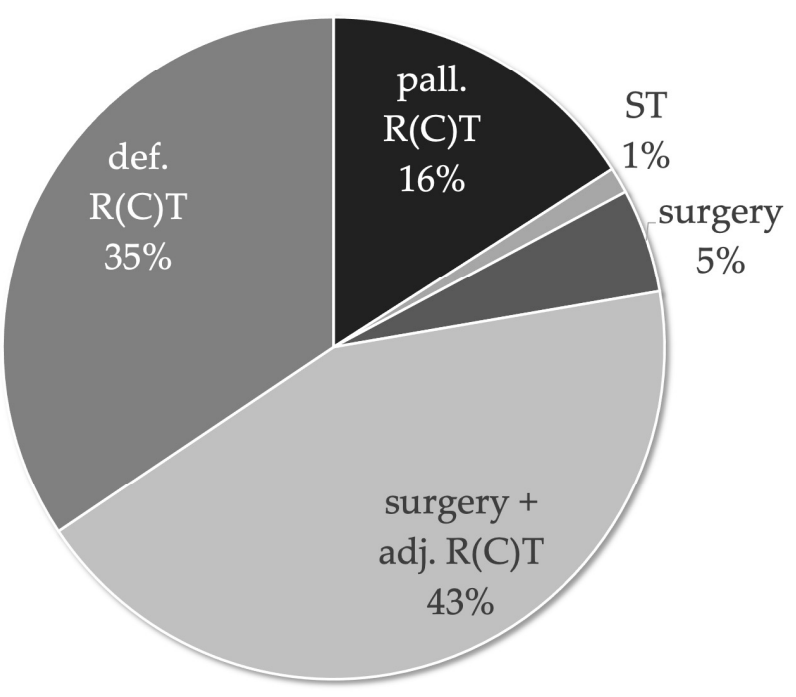

\section{B. Treatment received}

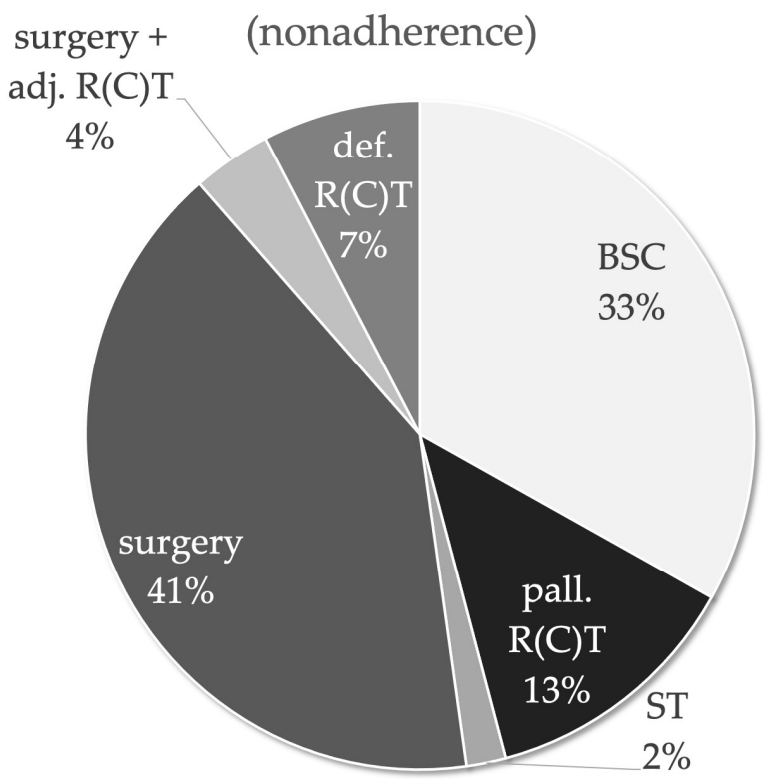

Figure 2. Treatment recommendations of the multidisciplinary tumour board of the nonadherent HNSCC patients $\geq 70$ years. (A). Treatment recommended and (B). Treatment received by nonadherent patients.

There were no cases $(0.0 \%)$ in which the recommended palliative treatment in nonadherent patients was BSC, whereas it was palliative RT/RCT in 15.9\% of cases and ST in $1.3 \%$. By contrast, $33.1 \%$ of nonadherent patients actually received BSC, $12.7 \%$ of nonadherent patients received palliative RT/RCT and $1.9 \%$ of nonadherent patients received ST. Table 3 show a cross-table comparing the therapy recommended by the tumour board with the implementation of the therapy. In total, $28.0 \%(n=44)$ of the nonadherent patients rejected adjuvant RT/RCT after surgery, and $23.6 \%(n=37)$ of the nonadherent patients interrupted definitive RT/RCT. Three patients refused to complete surgery, i.e., opted not to undergo a recommended re-resection in R1 condition. Approximately 8.9\% $(n=14)$ of nonadherent patients discontinued palliative RT/RCT. Forty-eight patients with a curative treatment recommendation according to tumour board opted for a palliative approach including ST, $\mathrm{RT} / \mathrm{RCT}$ or BSC.

As previously mentioned, in $88.0 \%(n=990)$ of cases, the treatment originally recommended by the tumour board was curative. The clinicopathological data of this subgroup are summarised in Supplementary Tables S1-S3. Here, differences between adherent and nonadherent patients were found for the same characteristics as in the whole study population. 
Table 3. Cross-table comparing the therapy recommended by the tumour board to the implementation of the therapy.

\begin{tabular}{|c|c|c|c|c|c|}
\hline & & \multicolumn{2}{|c|}{ Nonadherent } & \multirow{2}{*}{$\begin{array}{c}\text { Adherent } \\
\text { Carried out }\end{array}$} & \multirow{2}{*}{ Total } \\
\hline & & Discontinued & Rejected & & \\
\hline \multirow{6}{*}{$\begin{array}{l}\text { Treatment } \\
\text { recommendation }\end{array}$} & Palliative/ BSC & $0(0.0 \%)$ & $0(0.0 \%)$ & $28(2.5 \%)$ & $28(2.5 \%)$ \\
\hline & Pall. R(C)T & $14(1.2 \%)$ & $11(1.0 \%)$ & $69(6.1 \%)$ & $94(8.4 \%)$ \\
\hline & ST & $0(0.0 \%)$ & $2(0.2 \%)$ & $11(1.0 \%)$ & $13(1.2 \%)$ \\
\hline & Surgery & $3(0.3 \%)$ & $5(0.4 \%)$ & $385(34.2 \%)$ & $393(34.9 \%)$ \\
\hline & Surgery + adj. R(C)T & $24(2.1 \%)$ & $44(3.9 \%)$ & $178(15.8 \%)$ & $246(21.9 \%)$ \\
\hline & Def. $R(C) T$ & $37(3.3 \%)$ & $17(1.5 \%)$ & $297(26.4 \%)$ & $351(31.2 \%)$ \\
\hline \multicolumn{2}{|c|}{ Total } & $78(6.9 \%)$ & $79(7.0 \%)$ & $968(86.0 \%)$ & $1125(100 \%)$ \\
\hline
\end{tabular}

BSC, Best Supportive Care; Pall. R(C)T, palliative radio(chemo)therapy; ST, systemic therapy; Adj. R(C)T, adjuvant radio(chemo)therapy; Def. $\mathrm{R}(\mathrm{C}) \mathrm{T}$, definitive radio(chemo)therapy.

\subsection{Long-Term Survival and Disease Free Survival}

The mean survival was 63 months (95\%CI 57.98-68.75). The 1-, 3- and 5-year OS rates were $70.2,51.6$ and $41.5 \%$, respectively (Figure $3 \mathrm{~A})$. Half of all patients $(n=627,55.7 \%)$ died during the follow-up period, and in $67.9 \%$, the patient's death was known to be cancer-related. In $77.5 \%$ of cancer-associated deaths $(n=330)$, the tumour stage was already advanced (UICC III-IV) at initial diagnosis. The mean DFS was 118 months (95\%CI 111.09-124.05). The 1-, 3and 5-year DFS rates were 86.0, 74.6 and 68.2\%, respectively (Figure 3C).
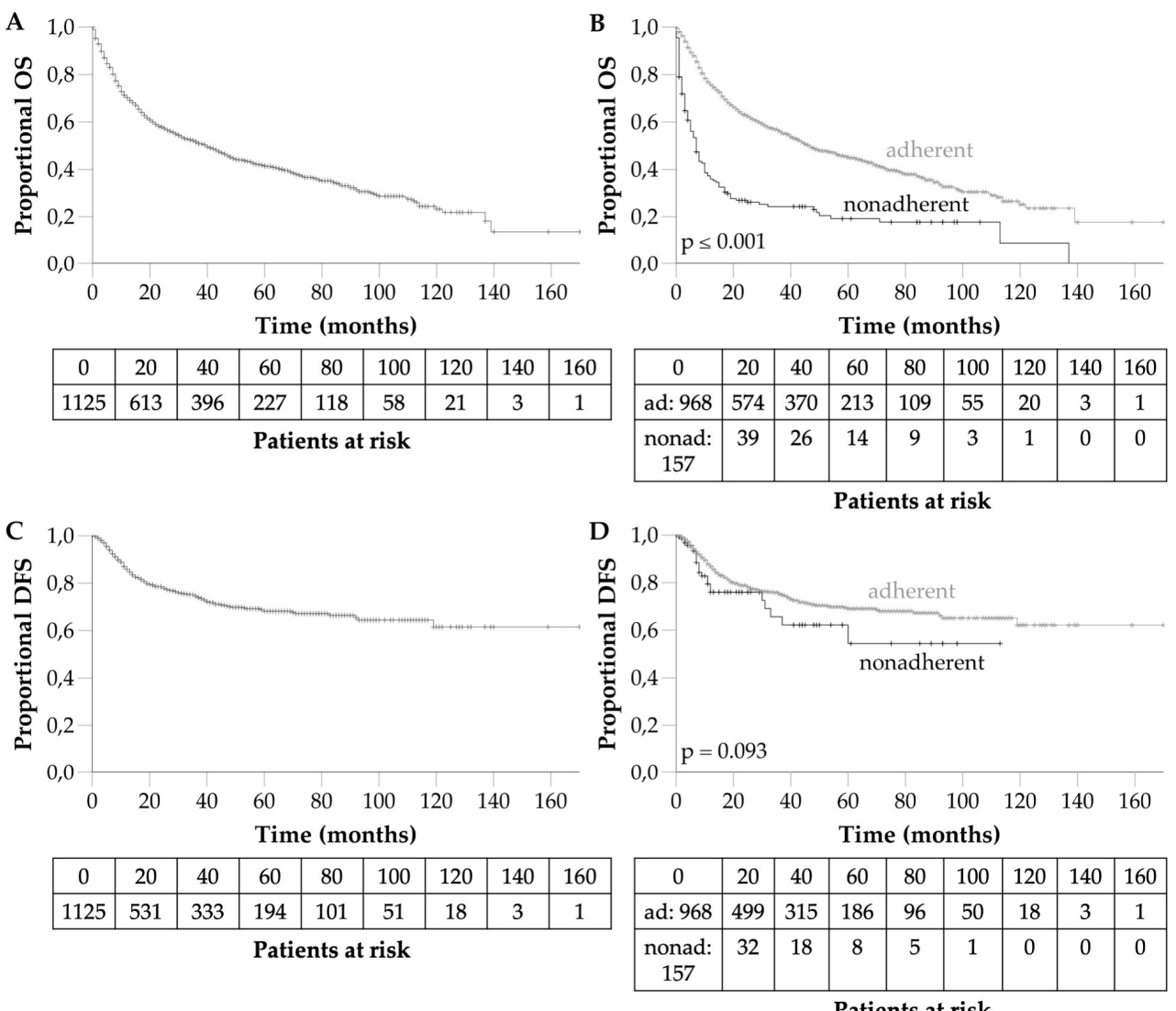

Figure 3. (A). Overall survival of the 1125 patients with HNSCC $\geq 70$ years. (B). Overall survival depending on adherence. (C). Disease-free survival of the 1125 patients with HNSCC $\geq 70$ years. (D). Disease-free survival depending on adherence. Ad, adherent; nonad, nonadherent. 


\subsection{Predictors for Survival}

Significant predictors for survival are summarised in Table 4 . They included both chronological age $(p \leq 0.001)$ and biological age (CCI, $p \leq 0.001)$, tobacco exposure $(p=0.001)$, alcohol abuse $(p \leq 0.001)$, good health (CCI $\leq 5, p \leq 0.001$ and KPS $\geq 80 \%, p \leq 0.001)$, T classification $(p \leq 0.001)$, lymph node involvement $(p \leq 0.001)$, distant metastases $(p \leq 0.001)$ and UICC stage $(p \leq 0.001)$. Long-term survival in nonadherent patients was significantly worse compared to adherent patients ( $p \leq 0.001$, Figure 3B). The 5-year OS was $45.1 \%$ for adherent patients compared to nonadherent patients (19.2\%). The DFS in nonadherent patients tended to be worse compared to adherent patients $(p=0.093$, Figure 3D). The multivariate analysis confirmed the independent influence on OS of chronological age, tobacco exposure, biological age, KPS, UICC stage and adherence to treatment recommendation.

In adherent patients, the predictors were mostly identical compared to the whole patient group (Table 4). In nonadherent patients, unlike in adherent patients, age, tobacco exposure, T classification, distal metastases, UICC stage and tumour site did not have any significant impact. 
Table 4. Univariate and multivariate analysis of clinicopathologic variables associated with overall survival (Table S4).

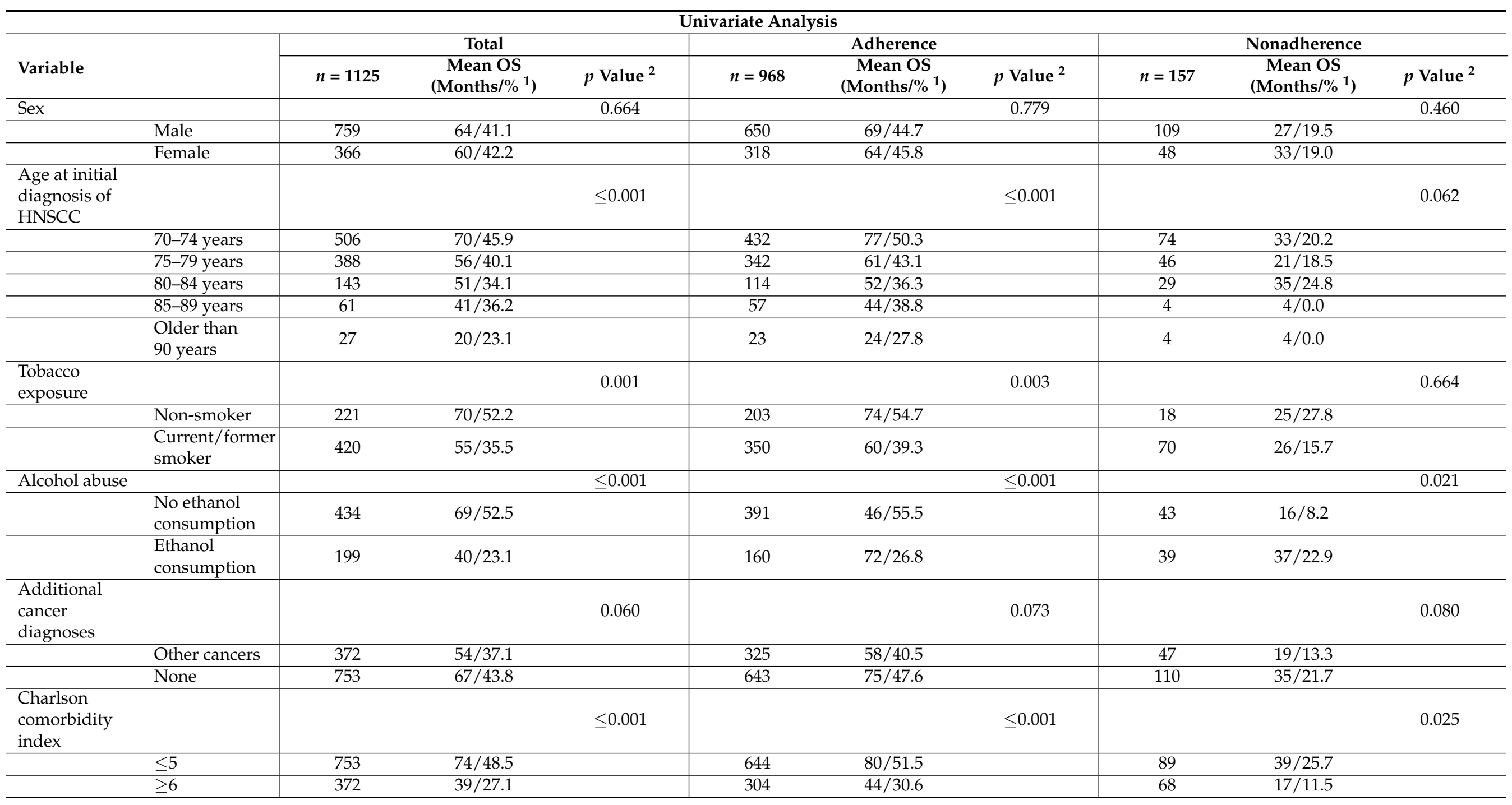


Table 4. Cont.

\begin{tabular}{|c|c|c|c|c|c|c|c|c|c|c|}
\hline \multicolumn{11}{|c|}{ Univariate Analysis } \\
\hline \multirow[b]{2}{*}{ Variable } & & \multicolumn{3}{|c|}{ Total } & \multicolumn{3}{|c|}{ Adherence } & \multicolumn{3}{|c|}{ Nonadherence } \\
\hline & & $n=1125$ & $\begin{array}{c}\text { Mean OS } \\
\left(\text { Months } / \%{ }^{1} \text { ) }\right.\end{array}$ & $p$ Value $^{2}$ & $n=968$ & $\begin{array}{c}\text { Mean OS } \\
\text { (Months/\% }{ }^{1} \text { ) }\end{array}$ & $p$ Value $^{2}$ & $n=157$ & $\begin{array}{c}\text { Mean OS } \\
\left(\text { Months } / \%{ }^{1}\right)^{2}\end{array}$ & $p$ Value $^{2}$ \\
\hline $\begin{array}{l}\text { Karnofsky } \\
\text { performance } \\
\text { status }\end{array}$ & & & & $\leq 0.001$ & & & $\leq 0.001$ & & & 0.004 \\
\hline & $\leq 70 \%$ & 604 & $37 / 22.8$ & & 482 & $41 / 25.2$ & & 122 & $23 / 13.5$ & \\
\hline & $\geq 80 \%$ & 521 & $90 / 62.4$ & & 486 & $93 / 64.2$ & & 35 & $55 / 37.3$ & \\
\hline $\begin{array}{l}\text { Site of primary } \\
\text { tumour }\end{array}$ & & & & $\leq 0.001$ & & & $\leq 0.001$ & & & 0.361 \\
\hline & Oropharynx & 305 & $64 / 41.6$ & & 252 & $72 / 47.2$ & & 53 & $22 / 11.8$ & \\
\hline & Oral cavity & 449 & $56 / 42.9$ & & 393 & $58 / 45.4$ & & 56 & $34 / 25.2$ & \\
\hline & Larynx & 215 & $85 / 50.9$ & & 186 & $92 / 56.2$ & & 29 & $37 / 23.9$ & \\
\hline & Hypopharynx & 95 & $31 / 15.4$ & & 81 & $25 / 14.9$ & & 14 & $22 / 14.3$ & \\
\hline & $\begin{array}{l}\text { Paranasal } \\
\text { sinus }\end{array}$ & 43 & $56 / 43.4$ & & 39 & $60 / 45.0$ & & 4 & $23 / 0.0$ & \\
\hline & Nasopharynx & 18 & $29 / 25.8$ & & 17 & $30 / 27.5$ & & 1 & $6 / 0.0$ & \\
\hline $\begin{array}{l}\text { P16 in } \\
\text { Oropharynx- } \\
\text { Carcinoma }\end{array}$ & & & & 0.191 & & & 0.198 & & & 0.329 \\
\hline & Positive & 93 & $72 / 49.1$ & & 75 & $80 / 55.7$ & & 18 & $23 / 0.0$ & \\
\hline & Negative & 89 & $54 / 39.7$ & & 75 & $59 / 44.8$ & & 14 & $17 / 10.7$ & \\
\hline Grading & & & & 0.018 & & & 0.188 & & & 0.214 \\
\hline & G1 & 105 & $64 / 53.4$ & & 99 & $66 / 54.2$ & & 6 & $34 / 50.0$ & \\
\hline & G2 & 657 & $65 / 41.9$ & & 569 & $70 / 45.4$ & & 88 & $27 / 19.1$ & \\
\hline & G3 & 253 & $55 / 37.0$ & & 204 & $61 / 42.4$ & & 49 & $24 / 13.4$ & \\
\hline T classification & & & & $\leq 0.001$ & & & $\leq 0.001$ & & & 0.064 \\
\hline & $\mathrm{T} 1-2$ & 586 & $86 / 54.9$ & & 536 & $89 / 57.3$ & & 50 & $40 / 30.0$ & \\
\hline & T3-4 & 539 & $41 / 26.9$ & & 432 & $45 / 30.0$ & & 107 & $27 / 14.1$ & \\
\hline $\begin{array}{l}\mathrm{N} \\
\text { classification }\end{array}$ & & & & $\leq 0.001$ & & & $\leq 0.001$ & & & 0.012 \\
\hline & Positive & 543 & $48 / 29.5$ & & 445 & $53 / 33.1$ & & 98 & $22 / 12.9$ & \\
\hline & Negative & 582 & $76 / 52.5$ & & 523 & $83 / 55.2$ & & 59 & $45 / 29.1$ & \\
\hline
\end{tabular}


Table 4. Cont.

\begin{tabular}{|c|c|c|c|c|c|c|c|c|c|c|}
\hline \multicolumn{11}{|c|}{ Univariate Analysis } \\
\hline \multirow[b]{2}{*}{ Variable } & & \multicolumn{3}{|c|}{ Total } & \multicolumn{3}{|c|}{ Adherence } & \multicolumn{3}{|c|}{ Nonadherence } \\
\hline & & $n=1125$ & $\begin{array}{c}\text { Mean OS } \\
\text { (Months/\% }{ }^{1} \text { ) }\end{array}$ & $p$ Value $^{2}$ & $n=968$ & $\begin{array}{c}\text { Mean OS } \\
\text { (Months/\% }{ }^{1} \text { ) }\end{array}$ & $p$ Value $^{2}$ & $n=157$ & $\begin{array}{c}\text { Mean OS } \\
\left(\text { Months } / \%{ }^{1}\right)^{2}\end{array}$ & $p$ Value $^{2}$ \\
\hline $\begin{array}{l}\text { M } \\
\text { classification }\end{array}$ & & & & $\leq 0.001$ & & & $\leq 0.001$ & & & 0.182 \\
\hline & Positive & 44 & $9 / 0.0$ & & 34 & $9 / 0.0$ & & 10 & $7 / 12.5$ & \\
\hline & Negative & 1081 & $65 / 42.9$ & & 934 & $71 / 46.5$ & & 147 & $32 / 19.9$ & \\
\hline $\begin{array}{l}\text { UICC stage } \\
\text { (8th edition) }\end{array}$ & & & & $\leq 0.001$ & & & $\leq 0.001$ & & & 0.333 \\
\hline & I-II & 451 & $93 / 61.4$ & & 422 & $96 / 63.6$ & & 29 & $34 / 29.8$ & \\
\hline & III-IV & 674 & $45 / 28.5$ & & 546 & $49 / 31.2$ & & 128 & $29 / 16.8$ & \\
\hline $\begin{array}{l}\text { Treatment } \\
\text { received }\end{array}$ & & & & $\leq 0.001$ & & & $\leq 0.001$ & & & $\leq 0.001$ \\
\hline & $\begin{array}{l}\text { Palliative/ } \\
\text { BSC }\end{array}$ & 80 & $6 / 0.0$ & & 28 & $7 / 0.0$ & & 52 & $5 / 4.3$ & \\
\hline & Pall. R(C)T & 89 & $12 / 9.9$ & & 69 & $12 / 10.2$ & & 20 & $10 / 10.0$ & \\
\hline & Surgery & 449 & $91 / 62.9$ & & 385 & $99 / 66.9$ & & 64 & $59 / 38.3$ & \\
\hline & $\begin{array}{l}\text { Surgery + adj. } \\
\mathrm{R}(\mathrm{C}) \mathrm{T}\end{array}$ & 184 & $65 / 40.6$ & & 178 & $66 / 40.7$ & & 6 & $31 / 33.3$ & \\
\hline & ST & 14 & $10 / 0.0$ & & 11 & $11 / 0.0$ & & 3 & $5 / 0.0$ & \\
\hline $\begin{array}{l}\text { Treatment rec- } \\
\text { ommendation }\end{array}$ & & & & $\leq 0.001$ & & & $\leq 0.001$ & & & $\leq 0.001$ \\
\hline & $\begin{array}{l}\text { Palliative/ } \\
\text { BSC }\end{array}$ & 28 & $7 / 0.0$ & & 28 & $7 / 0.0$ & & - & - & \\
\hline & Pall. R(C)T & 94 & $10 / 8.4$ & & 69 & $12 / 10.2$ & & 25 & $5 / 5.0$ & \\
\hline & Surgery & 393 & $97 / 65.5$ & & 385 & $99 / 66.9$ & & 8 & $5 / 0.0$ & \\
\hline & $\begin{array}{l}\text { Surgery + adj. } \\
\mathrm{R}(\mathrm{C}) \mathrm{T}\end{array}$ & 246 & $64 / 40.4$ & & 178 & $66 / 40.7$ & & 68 & $58 / 39.5$ & \\
\hline & Def. $R(C) T$ & 351 & $42 / 28.9$ & & 297 & $48 / 33.4$ & & 54 & $7 / 5.7$ & \\
\hline & ST & 13 & $9 / 0.0$ & & 11 & $11 / 0.0$ & & 2 & $1 / 0.0$ & \\
\hline
\end{tabular}


Table 4. Cont.

\begin{tabular}{|c|c|c|c|c|c|c|c|c|c|}
\hline \multicolumn{10}{|c|}{ Univariate Analysis } \\
\hline \multirow[b]{2}{*}{ Variable } & \multicolumn{3}{|c|}{ Total } & \multicolumn{3}{|c|}{ Adherence } & \multicolumn{3}{|c|}{ Nonadherence } \\
\hline & $n=1125$ & $\begin{array}{c}\text { Mean OS } \\
\text { (Months/\% }{ }^{1} \text { ) }\end{array}$ & $p$ Value $^{2}$ & $n=968$ & $\begin{array}{c}\text { Mean OS } \\
\text { (Months/\% }{ }^{1} \text { ) }\end{array}$ & $p$ Value $^{2}$ & $n=157$ & $\begin{array}{c}\text { Mean OS } \\
\text { (Months/\% }{ }^{1} \text { ) }\end{array}$ & $p$ Value $^{2}$ \\
\hline $\begin{array}{l}\text { Adherence to } \\
\text { treatment rec- } \\
\text { ommendation }\end{array}$ & & & $\leq 0.001$ & & & - & & & - \\
\hline Adherent & 968 & $69 / 45.1$ & & - & - & & - & - & \\
\hline Nonadherent & 157 & $31 / 19.2$ & & - & - & & - & - & \\
\hline $\begin{array}{l}\text { Implementation } \\
\text { of therapy }\end{array}$ & & & $\leq 0.001$ & & & - & & & $\leq 0.001$ \\
\hline Discontinued & 78 & $13 / 8.5$ & & - & - & & 78 & $13 / 8.5$ & \\
\hline Rejected & 79 & $46 / 29.5$ & & & - & & 79 & $46 / 29.5$ & \\
\hline Carried out & 968 & $69 / 45.1$ & & 968 & $69 / 45.1$ & & - & - & \\
\hline $\begin{array}{l}\text { Intention of } \\
\text { therapy }\end{array}$ & & & $\leq 0.001$ & & & $\leq 0.001$ & & & $\leq 0.001$ \\
\hline Curative & 860 & $76 / 49.8$ & & 860 & $76 / 49.8$ & & - & - & \\
\hline Palliative & 183 & $9 / 5.1$ & & 108 & $11 / 5.9$ & & 75 & $7 / 5.7$ & \\
\hline $\begin{array}{l}\text { Curative, } \\
\text { discontinued }\end{array}$ & 82 & $49 / 32.7$ & & - & - & & 82 & $49 / 32.7$ & \\
\hline \multicolumn{10}{|c|}{ Multivariate Cox Regression Analysis } \\
\hline Variable & & \multicolumn{2}{|c|}{$n=1125$} & \multicolumn{2}{|c|}{ HR } & \multicolumn{2}{|c|}{$95 \% \mathrm{CI}$} & \multicolumn{2}{|c|}{$p$ Value } \\
\hline \multirow[t]{3}{*}{ Age of diagnosis } & & & & \multicolumn{2}{|c|}{1.401} & \multicolumn{2}{|c|}{$1.112-1.765$} & \multicolumn{2}{|c|}{0.004} \\
\hline & $\leq 75$ & \multicolumn{2}{|c|}{606} & & & & & & \\
\hline & $\geq 76$ & \multicolumn{2}{|c|}{519} & & & \multirow{2}{*}{\multicolumn{2}{|c|}{$1.065-1.778$}} & \multirow{2}{*}{\multicolumn{2}{|c|}{0.014}} \\
\hline \multirow[t]{3}{*}{ Tobacco exposure } & & & & \multicolumn{2}{|c|}{1.376} & & & & \\
\hline & Non-smoker & \multicolumn{2}{|c|}{221} & & & & & & \\
\hline & $\begin{array}{c}\text { Current/ } \\
\text { former smoker }\end{array}$ & \multicolumn{2}{|c|}{420} & & & & & & \\
\hline \multirow[t]{3}{*}{ Charlson comorbidity index } & & & & \multicolumn{2}{|c|}{1.419} & \multicolumn{2}{|c|}{$1.138-1.769$} & \multicolumn{2}{|c|}{0.002} \\
\hline & $\leq 5$ & & & & & & & & \\
\hline & $\geq 6$ & & & & & & & & \\
\hline
\end{tabular}


Table 4. Cont.

\begin{tabular}{|c|c|c|c|c|c|c|c|c|c|}
\hline \multicolumn{10}{|c|}{ Univariate Analysis } \\
\hline \multirow[b]{2}{*}{ Variable } & \multicolumn{3}{|c|}{ Total } & \multicolumn{3}{|c|}{ Adherence } & \multicolumn{3}{|c|}{ Nonadherence } \\
\hline & $n=1125$ & $\begin{array}{c}\text { Mean OS } \\
\left(\text { Months/\% }{ }^{1}\right)\end{array}$ & $p$ Value $^{2}$ & $n=968$ & $\begin{array}{c}\text { Mean OS } \\
\left(\text { Months/\% }{ }^{1}\right)\end{array}$ & $p$ Value $^{2}$ & $n=157$ & $\begin{array}{c}\text { Mean OS } \\
\left(\text { Months/\% }{ }^{1}\right)\end{array}$ & $p$ Value $^{2}$ \\
\hline \multicolumn{10}{|c|}{ Multivariate Cox Regression Analysis } \\
\hline \multirow[t]{3}{*}{ Karnofsky performance status } & & \multirow{2}{*}{\multicolumn{2}{|c|}{604}} & \multicolumn{2}{|c|}{0.536} & \multicolumn{2}{|c|}{$0.424-0.678$} & \multicolumn{2}{|c|}{$\leq 0.001$} \\
\hline & $\leq 70 \%$ & & & & & & & & \\
\hline & $\geq 80 \%$ & \multicolumn{2}{|c|}{521} & & & & & & \\
\hline \multirow[t]{3}{*}{ UICC stage (8th edition) } & & & & \multicolumn{2}{|c|}{2.040} & \multicolumn{2}{|c|}{$1.617-2.575$} & \multicolumn{2}{|c|}{$\leq 0.001$} \\
\hline & I-II & \multicolumn{2}{|c|}{451} & & & & & \\
\hline & III-IV & & & & & & & & \\
\hline \multirow[t]{3}{*}{$\begin{array}{l}\text { Adherence to treatment } \\
\text { recommendation }\end{array}$} & & & & \multicolumn{2}{|c|}{1.779} & \multicolumn{2}{|c|}{$1.349-2.345$} & \multicolumn{2}{|c|}{$\leq 0.001$} \\
\hline & Adherent & & & & & & & & \\
\hline & Nonadherent & & & & & & & & \\
\hline
\end{tabular}

noindentOS, overall survival; HNSCC, head and neck squamous cell carcinoma; UICC, Union for International Cancer Control; BSC, Best Supportive Care; Pall. R(C)T, palliative radio(chemo)therapy; ST, systemic therapy; Adj. $\mathrm{R}(\mathrm{C}) \mathrm{T}$, adjuvant radio(chemo)therapy; Def. $\mathrm{R}(\mathrm{C}) \mathrm{T}$, definitive radio(chemo)therapy. ${ }^{1}$ Proportion of patients alive after a follow-up period of 60 months. ${ }^{2}$ The $p$-values for the univariate analysis were determined using the log-rank test. 


\section{Discussion}

This study attempted to find predictors for nonadherence to a recommended treatment regimen in elderly patients with HNSCC. The study included 1125 patients older than 70 (and up to 100). The 5-year OS was $41.5 \%$. Predictors for survival included age, tobacco exposure, alcohol abuse, good health, T classification, lymph node involvement, distant metastases, UICC stage and adherence to the recommended treatment. These factors are comparable with the literature [21-28].

Since the definition of "elderly patients" with HNSCC varies in the literature, we decided to set our threshold age at $\geq 70$. Even though this age limit is commonly used in other studies [29-31], there are also different interpretations. Some authors have used a lower (60 and 65 years) $[32,33]$ or higher ( 80 years) $[34,35]$ minimum age.

We also found some studies on the question of what distinguishes patients who were treated according to the guideline and were adherent from those who were nonadherent $[6,7,22,36,37]$. The studies used different guidelines as a basis for their research. Derks et al. [7] and Dronkers et al. [6] used the national guidelines published by the Comprehensive Cancer Centre the Netherlands (IKNL), Sanabria et al. [22] used hospital guidelines and Kusaba et al. [36] did not elaborate on the term standard therapy and referred to it as curative recommended therapy. Our approach is most consistent with the definition of Roden et al. [37], in which the recommended therapy is defined as standard therapy in accordance with the National Comprehensive Cancer Network (NCCN) guidelines, including patient-specific treatment [38].

In accordance with previous studies, we showed that patients who followed the treatment advice of the multidisciplinary tumour board benefited from a higher OS than patients who discontinued or declined a proposed therapy $[6,22,36]$. In this context, our results differed significantly from those of Roden et al. [37]. In their study, no significant difference in OS was found between the two patient groups. However, in this study, patients who refused therapy were grouped in the nonadherent group together with those who discontinued therapy. The reasons for discontinuation of therapy were not systematically recorded, but often it was due to deterioration of patients' general condition that did not allow continuation of therapy and was often accompanied by earlier deaths.

Positive smoking status significantly reduces OS in HNSCC patients [23-25]. According to our research, however, this finding does not apply to the group of nonadherent patients. It appears that when patients deviate from their recommended therapy, smoking status no longer has an impact on OS. The same applies to alcohol abuse.

The tumour stage was a predictive factor for declining or discontinuing a recommended treatment $[6,7,22]$. With the increasing complexity of the recommended therapy, the adherence to the recommendation decreased. Approximately $28.0 \%$ of the nonadherent patients denied adjuvant RT/RCT after surgery, and $23.6 \%$ of the nonadherent patients interrupted definitive RT/RCT. The reason for this could be the longer duration of therapy if definitive RT/RCT or surgery with adjuvant RT/RCT are applied. In addition, the fear of side effects, especially from radiation and chemotherapy, could play a role. Furthermore, patients could be satisfied with their putative cancer-free condition after surgery without taking into consideration the importance of adjuvant therapy. Forty-eight patients with curative treatment recommended according to the tumour board received palliative care including ST, RT/RCT or BSC.

In elderly patients, there is a high prevalence of comorbidities. Advanced comorbidity has been shown to cause a marked reduction in life span in patients with HNSCC [26-28], as was corroborated by this study. Comorbidities cause an increased number of severe complications regardless of the therapy type $[27,39]$. It was previously shown that both KPS and CCI could serve as predictors for OS independently from one another [40]. This is supported by our multivariate analysis. Comorbidities are also an important prognostic factor in elderly patients receiving a standard curative treatment $[6,7,22,41]$.

In this study, biological age and patient health were significant predictors for adherence in contrast to chronological age. However, it is difficult to compare the different studies in 
detail, as no uniform index was used to evaluate the comorbidities. For example, the KaplanFeinstein Index or the Adult Comorbidity Evaluation-27 (ACE-27) were used [6,7,22,28,42]. The CCI was used by Roden et al. [37], and in contrast to our current study, they could not identify any difference between both groups. One reason may be that considerably more patients were included (1125 vs. 159 patients) in our studies. This study confirms that the health status determined by KPS is an important factor for nonadherence $[7,22]$.

There are other studies that partly address our objective and take greater account of the social status of the patients. For example, some studies suggest that marital status has an important impact on patients' treatment (not limited to but including HNSCC patients) $[6,7,43]$. The lack of information on patients' social networks may be the main drawback of this study. Another interesting aspect is the patients' attitude to life. Even though being cured is the highest priority among patients in all age groups, it is quite conceivable that older patients, who usually make up a smaller proportion of the study participants, have different priorities and value quality of life to a higher degree $[15,44]$. Future research remains desirable due to the purely retrospective character of this study.

\section{Conclusions}

This study gives a comprehensive overview of clinicopathological data on elderly patients suffering from HNSCC treated at a large head and neck tumour centre in Germany. In contrast to chronological patient age, biological age was identified as a significant predictor for adherence. Further predictors for nonadherence include smoking, alcohol abuse, health status, tumour stage and complex therapy such as surgery with adjuvant RT/RCT. These findings need to be verified by prospective study designs.

Supplementary Materials: The following are available online at https: / www.mdpi.com/article / 10.3390/cancers14020423/s1, Table S1: Patient and tumour characteristics of the study population treated with curative intent according to adherence/nonadherence to the tumour board recommendation, Table S2: Cross-table comparing the recommended therapy to the received therapy in patients with a curative recommendation, Table S3: Cross-table comparing the therapy recommended by the tumour board to the implementation of the therapy in patients with a curative recommendation, Table S4: Univariate and multivariate analysis of clinicopathologic variables associated with overall survival of patients with a curative recommendation.

Author Contributions: Conceptualisation, R.G., C.S. and A.C.; formal analysis, R.G. and A.C.; data curation, R.G. and A.C.; writing-original draft preparation, R.G., C.S. and A.C.; writing-review and editing R.G., C.S., M.H., C.D., V.M.H., K.K., I.T., H.O., M.B., P.A., S.D., I.P. and A.C.; visualisation, R.G. and A.C.; resources, C.S., M.H., C.D., V.M.H., K.K., I.T., H.O., M.B., P.A., S.D., I.P. and A.C.; supervision, A.C. All authors have read and agreed to the published version of the manuscript.

Funding: This research received no external funding.

Institutional Review Board Statement: The study was conducted according to the guidelines of the Declaration of Helsinki and approved by the Ethics Committee of the Charité-Universitätsmedizin Berlin, Germany (EA1/256/20; 08.10.2020).

Informed Consent Statement: Patient consent was waived due to the retrospective character of this study.

Data Availability Statement: The data are presented in Tables 1-4 and Supplementary Material Tables S1-S4.

Conflicts of Interest: The authors declare no conflict of interest.

\section{References}

1. The World Bank. Life Expectancy at Birth, Total (Years), European Union. Available online: https://data.worldbank.org/ indicator/SP.DYN.LE00.IN?locations=EU\&name_desc=false (accessed on 31 March 2021).

2. The World Bank. Life Expectancy at Birth, Total (Years), Germany. Available online: https://data.worldbank.org/indicator/SP. DYN.LE00.IN?locations=DE\&name_desc=false (accessed on 30 August 2021). 
3. Smith, B.D.; Smith, G.L.; Hurria, A.; Hortobagyi, G.N.; Buchholz, T.A. Future of cancer incidence in the United States: Burdens upon an aging, changing nation. J. Clin. Oncol. 2009, 27, 2758-2765. [CrossRef] [PubMed]

4. Hurria, A.; Dale, W.; Mooney, M.; Rowland, J.H.; Ballman, K.V.; Cohen, H.J.; Muss, H.B.; Schilsky, R.L.; Ferrell, B.; Extermann, M.;et al. Designing therapeutic clinical trials for older and frail adults with cancer: U13 conference recommendations. J. Clin. Oncol. 2014, 32, 2587-2594. [CrossRef]

5. De Felice, F.; Vetrone, L.; Bulzonetti, N.; Caiazzo, R.; Marampon, F.; Musio, D.; Tombolini, V. Hypofractionated radiotherapy combined with cetuximab in vulnerable elderly patients with locally advanced head and neck squamous cell carcinoma. Med. Oncol. 2019, 36, 68. [CrossRef] [PubMed]

6. $\quad$ Dronkers, E.A.; Mes, S.W.; Wieringa, M.H.; van der Schroeff, M.P.; Baatenburg de Jong, R.J. Noncompliance to guidelines in head and neck cancer treatment; associated factors for both patient and physician. BMC Cancer 2015, 15, 515. [CrossRef] [PubMed]

7. Derks, W.; de Leeuw, J.R.; Hordijk, G.J.; Winnubst, J.A. Reasons for non-standard treatment in elderly patients with advanced head and neck cancer. Eur. Arch. Otorhinolaryngol. 2005, 262, 21-26. [CrossRef]

8. Juarez, J.E.; Choi, J.; St John, M.; Abemayor, E.; TenNapel, M.; Chen, A.M. Patterns of Care for Elderly Patients With Locally Advanced Head and Neck Cancer. Int. J. Radiat. Oncol. Biol. Phys. 2017, 98, 767-774. [CrossRef]

9. Lop, J.; Valero, C.; Garcia, J.; Quer, M.; Ganly, I.; Shah, J.P.; Patel, S.G.; Leon, X. Does age influence disease-specific survival in patients with squamous cell carcinomas of the head and neck? J. Surg. Oncol. 2020, 121, 1058-1066. [CrossRef] [PubMed]

10. Coca-Pelaz, A.; Halmos, G.B.; Strojan, P.; de Bree, R.; Bossi, P.; Bradford, C.R.; Rinaldo, A.; Vander Poorten, V.; Sanabria, A.; Takes, R.P.; et al. The role of age in treatment-related adverse events in patients with head and neck cancer: A systematic review. Head Neck 2019, 41, 2410-2429. [CrossRef] [PubMed]

11. VanderWalde, N.A.; Fleming, M.; Weiss, J.; Chera, B.S. Treatment of older patients with head and neck cancer: A review. Oncologist 2013, 18, 568-578. [CrossRef]

12. Rim, C.H.; Yoon, W.S.; Lee, J.A.; Yang, D.S.; Lee, N.K.; Park, Y.J.; Kim, C.Y. Factors predicting intolerance to definitive conventional radiotherapy in geriatric patients. Strahlenther. Onkol. 2018, 194, 894-903. [CrossRef]

13. Syrigos, K.N.; Karachalios, D.; Karapanagiotou, E.M.; Nutting, C.M.; Manolopoulos, L.; Harrington, K.J. Head and neck cancer in the elderly: An overview on the treatment modalities. Cancer Treat. Rev. 2009, 35, 237-245. [CrossRef] [PubMed]

14. Laccourreye, O.; Malinvaud, D.; Holsinger, F.C.; Consoli, S.; Menard, M.; Bonfils, P. Trade-off between survival and laryngeal preservation in advanced laryngeal cancer: The otorhinolaryngology patient's perspective. Ann. Otol. Rhinol. Laryngol. 2012, 121, 570-575. [CrossRef]

15. Yellen, S.B.; Cella, D.F.; Leslie, W.T. Age and clinical decision making in oncology patients. J. Natl. Cancer Inst. 1994, 86, 1766-1770. [CrossRef] [PubMed]

16. Haase, K.; Piwonski, I.; Stromberger, C.; Thieme, N.; Heiland, M.; Beck-Broichsitter, B.; Hofmann, V.M.; Kofla, G.; Sander, S.; Keilholz, U.; et al. Incidence and survival of HNSCC patients living with HIV compared with HIV-negative HNSCC patients. Eur. Arch. Otorhinolaryngol. 2021, 278, 3941-3953. [CrossRef] [PubMed]

17. Brierley, J.D.; Gospodarowicz, M.K.; Wittekind, C. TNM Classification of Malignant Tumours, 8th ed.; John Wiley \& Sons: Chichester, West Sussex, UK, 2017.

18. Karnofsky, D.A.; Abelmann, W.H.; Craver, L.F.; Burchenal, J.H. The use of the nitrogen mustards in the palliative treatment of carcinoma. Cancer 1948, 1, 634-656. [CrossRef]

19. Charlson, M.E.; Pompei, P.; Ales, K.L.; MacKenzie, C.R. A new method of classifying prognostic comorbidity in longitudinal studies: Development and validation. J. Chronic Dis. 1987, 40, 373-383. [CrossRef]

20. Lang, T.A.; Altman, D.G. Basic statistical reporting for articles published in biomedical journals: The "Statistical Analyses and Methods in the Published Literature" or the SAMPL Guidelines. Int. J. Nurs. Stud. 2015, 52, 5-9. [CrossRef]

21. Stromberger, C.; Yedikat, B.; Coordes, A.; Tinhofer, I.; Kalinauskaite, G.; Budach, V.; Zschaeck, S.; Raguse, J.D.; Kofla, G.; Heiland, M.; et al. Prognostic Factors Predict Oncological Outcome in Older Patients With Head and Neck Cancer Undergoing Chemoradiation Treatment. Front. Oncol. 2020, 10, 566318. [CrossRef]

22. Sanabria, A.; Carvalho, A.L.; Vartanian, J.G.; Magrin, J.; Ikeda, M.K.; Kowalski, L.P. Factors that influence treatment decision in older patients with resectable head and neck cancer. Laryngoscope 2007, 117, 835-840. [CrossRef]

23. Haehl, E.; Ruhle, A.; David, H.; Kalckreuth, T.; Sprave, T.; Stoian, R.; Becker, C.; Knopf, A.; Grosu, A.L.; Nicolay, N.H. Radiotherapy for geriatric head-and-neck cancer patients: What is the value of standard treatment in the elderly? Radiat. Oncol. 2020, 15, 31. [CrossRef]

24. Duffy, S.A.; Ronis, D.L.; McLean, S.; Fowler, K.E.; Gruber, S.B.; Wolf, G.T.; Terrell, J.E. Pretreatment health behaviors predict survival among patients with head and neck squamous cell carcinoma. J. Clin. Oncol. 2009, 27, 1969-1975. [CrossRef]

25. Sharp, L.; McDevitt, J.; Carsin, A.E.; Brown, C.; Comber, H. Smoking at diagnosis is an independent prognostic factor for cancer-specific survival in head and neck cancer: Findings from a large, population-based study. Cancer Epidemiol. Biomark. Prev. 2014, 23, 2579-2590. [CrossRef] [PubMed]

26. Sanabria, A.; Carvalho, A.L.; Vartanian, J.G.; Magrin, J.; Ikeda, M.K.; Kowalski, L.P. Comorbidity is a prognostic factor in elderly patients with head and neck cancer. Ann. Surg. Oncol. 2007, 14, 1449-1457. [CrossRef] [PubMed]

27. Singh, B.; Bhaya, M.; Stern, J.; Roland, J.T.; Zimbler, M.; Rosenfeld, R.M.; Har-El, G.; Lucente, F.E. Validation of the Charlson comorbidity index in patients with head and neck cancer: A multi-institutional study. Laryngoscope 1997, 107, 1469-1475. [CrossRef] [PubMed] 
28. Piccirillo, J.F. Importance of comorbidity in head and neck cancer. Laryngoscope 2000, 110, 593-602. [CrossRef]

29. Dequanter, D.; Shahla, M.; Paulus, P.; Boutremans, E.; Lothaire, P. Should older head and neck patients be treated differently? Eur. Ann. Otorhinolaryngol. Head Neck Dis. 2011, 128, 165-168. [CrossRef] [PubMed]

30. Srinivasalu, V.K.; Subramaniam, N.; Balasubramanian, D.; Kumar, N.; Philip, A.; Susan, A.; Pushpaja, K.U.; Nair, A.R.; Thankappan, K.; Jose, W.; et al. Concurrent chemoradiotherapy for head and neck cancers in older patients: Outcomes and their determinants. Indian J. Cancer 2019, 56, 261-266. [CrossRef]

31. Okuyama, K.; Yanamoto, S.; Michi, Y.; Shibata, E.; Tsuchiya, M.; Yokokawa, M.; Naruse, T.; Tomioka, H.; Kuroshima, T.; Shimamoto, H.; et al. Multicenter retrospective analysis of clinicopathological features and prognosis of oral tongue squamous cell carcinoma in adolescent and young adult patients. Medicine 2021, 100, e27560. [CrossRef]

32. Hasegawa, Y.; Fukuhara, T.; Fujiwara, K.; Takeuchi, E.; Kitano, H. Treatment Outcomes of Head and Neck Squamous Cell Carcinoma in the Elderly: A Retrospective Study over 7 Years (2003-2009). Yonago Acta Med. 2015, 58, 9-13.

33. Chen, Y.; Cao, W.; Gao, X.; Ong, H.; Ji, T. Predicting postoperative complications of head and neck squamous cell carcinoma in elderly patients using random forest algorithm model. BMC Med. Inform. Decis Mak. 2015, 15, 44. [CrossRef]

34. Bhama, P.K.; Patel, S.A.; Khan, U.; Bhrany, A.D.; Futran, N.D. Head and neck free flap reconstruction in patients older than 80 years. J. Reconstr. Microsurg. 2014, 30, 523-530. [CrossRef]

35. Clayman, G.L.; Eicher, S.A.; Sicard, M.W.; Razmpa, E.; Goepfert, H. Surgical outcomes in head and neck cancer patients 80 years of age and older. Head Neck 1998, 20, 216-223. [CrossRef]

36. Kusaba, R.; Sakamoto, K.; Mori, K.; Umeno, T.; Nakashima, T. Laboratory data and treatment outcomes of head and neck tumor patients in the elderly. Auris Nasus Larynx 2001, 28, 161-168. [CrossRef]

37. Roden, D.; Daniels, K.; Metkus, J.; Goldman, R.; Walsh, A.; Johnson, J.; Hamilton, J.; Keane, W.; Chapman, A.; Bar-Ad, V.; et al. Evaluation of oncologic outcomes in head and neck cancer patients $>/=80$ years old based on adherence to NCCN guideline for postoperative adjuvant treatment. Head Neck 2019, 41, 4128-4135. [CrossRef]

38. National Comprehensive Cancer Network. NCCN Guidelines. Available online: https://www.nccn.org/guidelines/guidelinesdetail?category $=1 \&$ id $=1437$ (accessed on 29 November 2021).

39. Borggreven, P.A.; Kuik, D.J.; Quak, J.J.; de Bree, R.; Snow, G.B.; Leemans, C.R. Comorbid condition as a prognostic factor for complications in major surgery of the oral cavity and oropharynx with microvascular soft tissue reconstruction. Head Neck 2003, 25, 808-815. [CrossRef] [PubMed]

40. Firat, S.; Byhardt, R.W.; Gore, E. Comorbidity and Karnofksy performance score are independent prognostic factors in stage III non-small-cell lung cancer: An institutional analysis of patients treated on four RTOG studies. Radiation Therapy Oncology Group. Int. J. Radiat. Oncol. Biol. Phys. 2002, 54, 357-364. [CrossRef]

41. Fang, P.; He, W.; Gomez, D.R.; Hoffman, K.E.; Smith, B.D.; Giordano, S.H.; Jagsi, R.; Smith, G.L. Influence of Age on GuidelineConcordant Cancer Care for Elderly Patients in the United States. Int. J. Radiat. Oncol. Biol. Phys. 2017, 98, 748-757. [CrossRef] [PubMed]

42. Kaplan, M.H.; Feinstein, A.R. The importance of classifying initial co-morbidity in evaluating the outcome of diabetes mellitus. J. Chronic Dis. 1974, 27, 387-404. [CrossRef]

43. Silliman, R.A.; Troyan, S.L.; Guadagnoli, E.; Kaplan, S.H.; Greenfield, S. The impact of age, marital status, and physician-patient interactions on the care of older women with breast carcinoma. Cancer 1997, 80, 1326-1334. [CrossRef]

44. Gill, S.S.; Frew, J.; Fry, A.; Adam, J.; Paleri, V.; Dobrowsky, W.; Chatterjee, S.; Kelly, C.G. Priorities for the head and neck cancer patient, their companion and members of the multidisciplinary team and decision regret. Clin. Oncol. 2011, 23, 518-524. [CrossRef] 